\title{
Synthesis, Structure, and Optical and Electrochemical Properties of Star-Shaped Porphyrin-Triarylamine Conjugates
}

\author{
Wei-Nan Yen, ${ }^{\dagger}$ Shang-Shih Lo, ${ }^{\dagger}$ Ming-Cheng Kuo, ${ }^{\dagger}$ Chi-Lun Mai, ${ }^{\dagger}$ \\ Gene-Hsiang Lee, ${ }^{\ddagger}$ Shie-Ming Peng, ${ }^{\ddagger}$ and Chen-Yu Yeh ${ }^{\star}, \dagger$ \\ Department of Chemistry and Center of Nanoscience and Nanotechnology, National \\ Chung Hsing University, Taichung 402, Taiwan, and Department of Chemistry, \\ National Taiwan University, Taipei 106, Taiwan
}

cyyeh@dragon.nchu.edu.tw

Received June 15, 2006

\section{ABSTRACT}
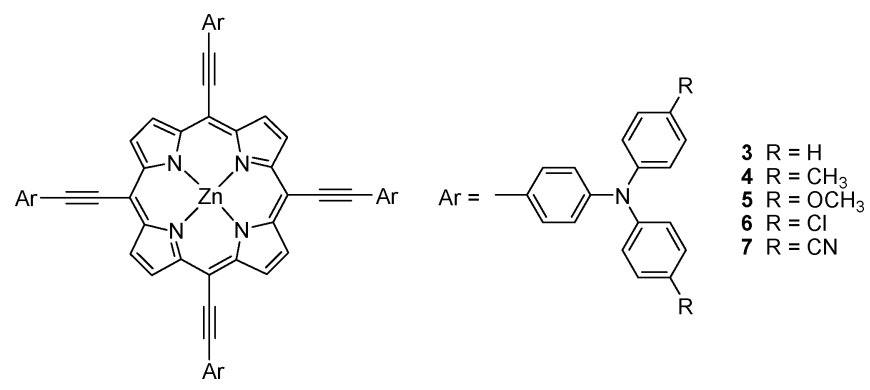

A series of novel star-shaped porphyrin-triarylamine conjugates were synthesized by palladium-catalyzed cross-coupling reactions. The spectroscopic and electrochemical studies show that $\pi$-conjugation of the porphyrin core is extended to the triarylamine moieties.

There has been continuous interest in the synthesis of porphyrins because they are widespread in nature ${ }^{1}$ and have promising applications in electronic materials. ${ }^{2}$ The physical and chemical properties of porphyrins can be precisely controlled by proper functionalization of the porphyrin core. In the meso-tetraarylporphyrins, the electronic perturbation is only moderate since the aryl groups twist out of the porphyrin plane resulting in the interruption of the $\pi$-conjugation. ${ }^{3}$ To increase the electronic interaction, numerous

† National Chung Hsing University.

$\doteqdot$ National Taiwan University.

(1) (a) Chapman, S. K.; Daff, S.; Munro, A. W. Structure and Bonding; Springer-Verlag: Berlin, Germany, 1997; Vol. 88, pp 39-70. (b) Kadish, K. M.; Smith, K. M.; Guilard, R. The Porphyrin Handbook; Academic Press: San Diego, CA, 2000. (c) Ortiz de Montellano, P. R. Cytochrome P450: Structure, Mechanism, and Biochemistry, 2nd ed.; Plenum: New York, 1995.

(2) (a) Anderson, H. L. Chem. Commun. 1999, 2323-2330. (b) Kim, D.; Osuka, A. J. Phys. Chem. A 2003, 107, 8791-8816. (c) Guldi, D. M.; Rahman, G. M. A.; Zerbetto, F.; Prato, M. Acc. Chem. Res. 2005, 38, 871878 . linkers have been used to bridge the aryl groups and the porphyrin. ${ }^{4}$ It has been reported that acetylenic types of linkers exhibit effective $\pi$-conjugation between aryl groups and the porphyrin core. ${ }^{4}$

Triarylamine-based oligomers and dendrimers have been intensively studied because of their potential applications in the field of organic light-emitting diode, information storage

(3) (a) Kim, J. B.; Leonard, J. J.; Longo, F. R. J. Am. Chem. Soc. 1972 94, 3986-3992. (b) Zuimby, D. J.; Longo, F. R. J. Am. Chem. Soc. 1975, 97, 5111-5117. (c) Spellane, P. J.; Gouterman, M.; Antipas, A.; Kim, S.; Liu, Y. C. Inorg. Chem. 1980, 19, 386-391.

(4) (a) Anderson, H. L.; Wylie, A. P.; Prout, K. J. Chem. Soc., Perkin Trans. 1 1998, 1607-1611. (b) Screen, T. E. O.; Blake, I. M.; Rees, L. H.; Clegg, W.; Borwick, S. J.; Anderson, H. L. J. Chem. Soc., Perkin Trans. 1 2002, 320-329. (c) LeCours, S. M.; DiMagno, S. G.; Therien, M. J. J. Am. Chem. Soc. 1996, 118, 11854-11864. (d) Lin, V. S.-Y.; DiMagno, S. G.; Therien, M. J. Science 1994, 264, 1105-1111. (e) Arnold, D. P.; Heath, G. A.; James, D. A. J. Porphyrins Phthalocyanines 1999, 3, 5-31. (f) Wytko, J.; Berl, V.; McLaughlin, M.; Tykwinski, R. R.; Schreiber, M.; Diederich, F. Helv. Chim. Acta 1998, 81, 1964-1977. (g) Susumu, K.; Maruyama, H.; Kobayashi, H.; Tanaka, K. J. Mater. Chem. 2001, 11, 22622270. 
Table 1. Absorption, Emission, and Redox Data for Compounds $\mathbf{1}$ and $\mathbf{3}-\mathbf{7}^{a}$

\begin{tabular}{|c|c|c|c|c|c|c|c|c|c|c|}
\hline & \multirow{2}{*}{$\begin{array}{c}\text { fwhm, B-band/ } \\
\mathrm{cm}^{-1}(\mathrm{~nm})^{b}\end{array}$} & \multirow[b]{2}{*}{$f_{\mathrm{B}}{ }^{c}$} & \multirow{2}{*}{$\begin{array}{c}\text { fwhm, Q-band/ } \\
\mathrm{cm}^{-1}(\mathrm{~nm})\end{array}$} & \multirow[b]{2}{*}{$f_{\mathrm{Q}^{d}}$} & \multirow{2}{*}{$\begin{array}{l}\lambda_{\mathrm{em}}{ }^{e} \\
(\mathrm{~nm})\end{array}$} & \multicolumn{3}{|c|}{ oxidation (V) } & \multicolumn{2}{|c|}{ reduction (V) } \\
\hline & & & & & & $E_{1 / 2}(\mathrm{ox} 1)$ & $E_{1 / 2}(\mathrm{ox} 2)$ & $E_{1 / 2}(\mathrm{ox} 3)$ & $E_{1 / 2}(\operatorname{red} 1)$ & $E_{1 / 2}(\operatorname{red} 2)$ \\
\hline 1 & 379 (458) & $1.22^{f}$ & $481(646)$ & $0.09^{g}$ & 652,716 & 1.24 & & & -0.90 & -1.38 \\
\hline 3 & $1371(500)$ & 1.65 & $1019(702)$ & 0.39 & 727,801 & 0.87 & 1.09 & & -0.94 & -1.37 \\
\hline 4 & $1420(503)$ & 1.58 & 1018 (709) & 0.32 & 736,801 & 0.84 & 0.99 & 1.26 & -0.92 & -1.34 \\
\hline 5 & $1830(504)$ & 2.04 & $1174(713)$ & 0.41 & 742,799 & 0.76 & 0.94 & 1.03 & -0.97 & -1.35 \\
\hline 6 & $1181(497)$ & 1.26 & $932(696)$ & 0.22 & 716,800 & 0.90 & 1.12 & & -0.90 & -1.32 \\
\hline 7 & $918(490)$ & 1.78 & $800(684)$ & 0.24 & 700,799 & 1.06 & $1.42^{h}$ & & -0.78 & -1.23 \\
\hline
\end{tabular}

${ }^{a}$ The absorption and emission spectra were taken in $\mathrm{CH}_{2} \mathrm{Cl}_{2}$ and electrochemical data were recorded in THF. ${ }^{b}$ fwhm is the full width at half-maximum height; the number in parentheses is the absorption maximum. ${ }^{c}$ Oscillator strengths calculated over the region from 400 to $600 \mathrm{~nm} .{ }^{d}$ Oscillator strengths calculated over the region from 600 to $800 \mathrm{~nm} .{ }^{e}$ Emission maximum. ${ }^{f}$ Oscillator strengths calculated over the region from 400 to $500 \mathrm{~nm} .{ }^{g}$ Oscillator strengths calculated over the region from 500 to $700 \mathrm{~nm} .{ }^{h}$ Irreversible reaction.

devices, hole-transporting materials, field-effect transistors, and photovoltaic cells. ${ }^{5}$ In recent years, significant interest has focused on the synthesis of hybrid molecules containing triarylamine moiety. ${ }^{6}$ However, only a few examples of porphyrin-triarylamine hybrids have been reported. ${ }^{7}$ Our group has previously reported the synthesis of porphyrintriarylamine conjugates, in which two triarylamine units are attached to the porphyrin core via ethynyl linkers. ${ }^{8}$ The electrochemical studies showed that the triarylamine units display strong coupling via the diethynylporphyrin bridge. In this Letter we report a synthetic route to star-shaped porphyrin-triarylamine conjugates and their spectroscopic and electrochemical properties are presented.

While the synthesis and properties of meso-substituted tetraarylporphyrins have been intensively studied, the studies on the meso-tetraarylethynylporphyrins are relatively rare. ${ }^{9}$ Usually, 5,10,15,20-meso-tetraarylethynylporphyrins were synthesized from the reaction of pyrrole with the corresponding arylpropynal under Lindsey's conditions. ${ }^{10}$ To avoid the multistep syntheses of arylpropynal, we have developed a simple approach to this type of porphyrins by coupling of 5,10,15,20-tetraethynylporphyrin to the appropriate aryl iodides. ${ }^{11} \mathrm{We}$ extended the palladium-catalyzed

(5) (a) Yan, H.; Scott, B. J.; Huang, Q.; Marks, T. J. Adv. Mater. 2004, 16, 1948-1953. (b) Fuentes-Hernandez, C.; Thomas, J.; Termine, R.; Meredith, G.; Peyghambarian, N.; Kippelen, B.; Barlow, S.; Walker, G.; Marder, S. R.; Yamamoto, M.; Cammack, K.; Matsumoto, K. Appl. Phys. Lett. 2004, 85, 1877-1879. (c) Bender, T. P.; Graham, J. F.; Duff, J. M. Chem. Mater. 2001, 13, 4105-4111. (d) Majewski, L. A.; Schroeder, R.; Grell, M. Adv. Funct. Mater. 2005, 15, 1017-1022. (e) Satoh, N.; Nakashima, T.; Yamamoto, K. J. Am. Chem. Soc. 2005, 127, 13030-13038.

(6) (a) Wang, Y. Z.; Epstein, A. J. Acc. Chem. Res. 1999, 32, 217-224. (b) Chen, C.-T.; Lin, J.-S., Moturu, M. V. R. K.; Lin, Y.-W.; Yi, W.; Tao, Y.-T.; Chien, C.-H. Chem. Commun. 2005, 3980-3982. (c) Sengupta, S.; Sadhukhan, S. K.; Muhuri, S. Tetrahedron Lett. 2002, 43, 3521-3524.

(7) (a) Li, B.; Xu, X.; Sun, M.; Fu, Y.; Yu, G.; Liu, Y.; Bo, Z. Macromolecules 2006, 39, 456-461. (b) Frampton, M. J.; Beavington, R.; Lupton, J. M.; Samuel, I. D. W.; Burn, P. L. Synth. Met. 2001, 121, 16711672. (c) Huang, C.-W.; Chiu, K. Y.; Cheng, S.-H. Dalton Trans. 2005, 2417-2422.

(8) Chang, J.-C.; Ma, C.-J.; Lee, G.-H.; Peng, S.-M.; Yeh, C.-Y. Dalton Trans. 2005, 1504-1508.

(9) (a) Proess, G.; Pankert, D.; Hevesi, L. Tetrahedron Lett. 1992, 33 269-272. (b) Anderson, H. L. Tetrahedron Lett. 1992, 33, 1101-1104. (c) Milgrom, L. R.; Yahioglu, G. Tetrahedron Lett. 1995, 36, 9061-9064. (d) Milgrom, L. R.; Yahioglu, G. Tetrahedron Lett. 1996, 37, 4069-4072. (e) Anderson, H. L.; Wylie, A. P.; Prout, K. J. Chem. Soc., Perkin Trans. 1 1998, 1607-1611.

(10) Lindsey, J. S.; Wagner. R. W. J. Org. Chem. 1989, 54, 828-836. coupling method to the synthesis of star-shaped porphyrintriarylamine conjugates. As shown in Scheme 1, deprotection

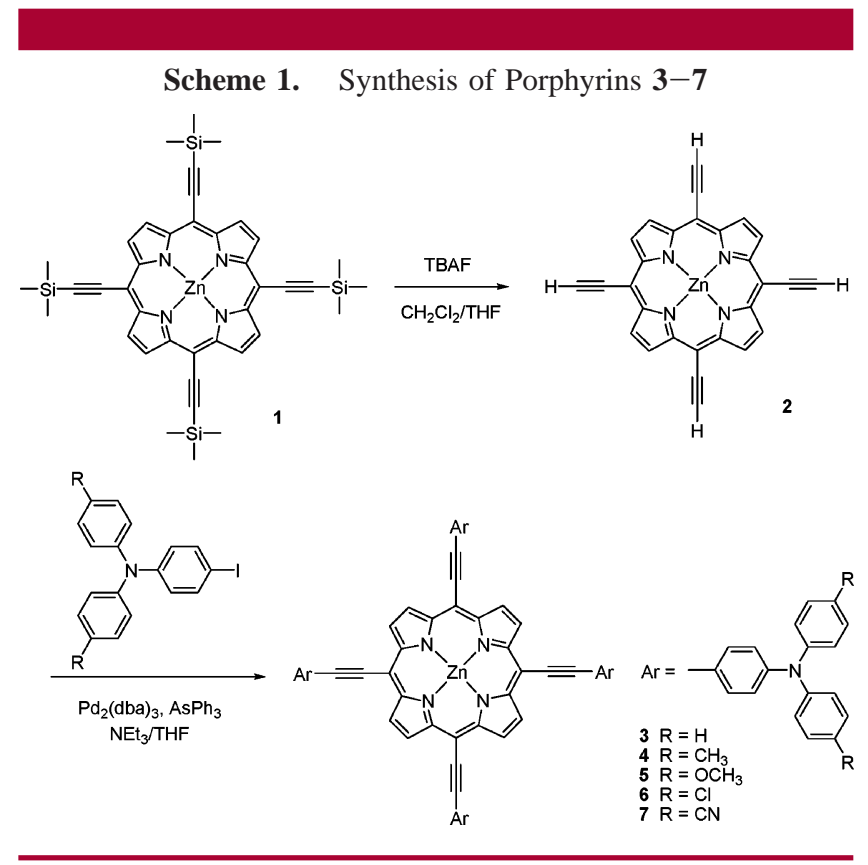

of porphyrin 1 by TBAF afforded the key intermediate porphyrin 2 , which was then coupled to 4 -( $N, N$-diarylamino)phenyl iodides to give the desired porphyrins 3-7. The coupling process proceeded efficiently for both electrondonating and electron-withdrawing substrates. The new compounds were characterized by various spectroscopic methods.

The electronic interaction between the triarylamine units and porphyrin macrocycle was investigated by UV-vis absorption spectroscopy. The electronic absorption data for porphyrins 3-7 and reference porphyrin $\mathbf{1}$ are summarized in Table 1. The absorption spectra of these conjugates are very different from the sum of their respective components, porphyrin 1 and the corresponding triarylamines, and show peak broadening, peak shifts, and changes in the oscillator

(11) Kuo, M.-C.; Yen, W.-N.; Lo S.-S.; Yeh, C.-Y. Manuscript in preparation. 


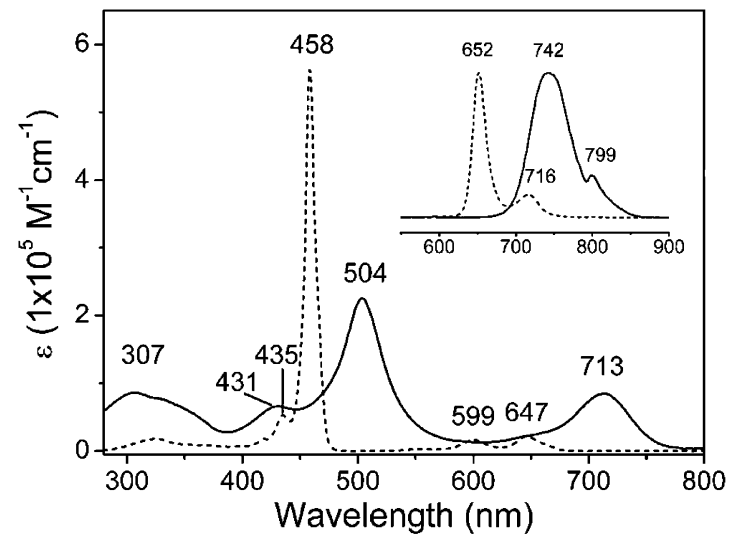

Figure 1. The absorption of $\mathbf{5}$ (solid) and $\mathbf{1}$ (dash) in $\mathrm{CH}_{2} \mathrm{Cl}_{2}$. Inset: Emission spectra, excited at 504 and $458 \mathrm{~nm}$ for $\mathbf{5}$ and 1, respectively.

strength of absorptions. ${ }^{12,13}$ As an example, Figure 1 shows the UV-vis spectra of compounds 1 and 5. In $\mathrm{CH}_{2} \mathrm{Cl}_{2}$, porphyrin 5 shows a Soret band at $504 \mathrm{~nm}$, representing the longest wavelength for a planar single porphyrin, together with a smaller Q-band at $713 \mathrm{~nm}$. The full width at halfmaximum height (fwhm) of the Soret bands is much larger for $5\left(1830 \mathrm{~cm}^{-1}\right)$ than for $\mathbf{1}\left(379 \mathrm{~cm}^{-1}\right)$, indicative of strong electronic interaction between the porphyrin and triarylamine units. The large red shifts of both the Soret and Q-bands indicate a decreased energy gap between the HOMO and LUMO orbitals as a consequence of the expanded $\pi$-conjugation. ${ }^{14,15}$ It should be noted that compounds 3-7 exhibit significantly enhanced oscillator strength of the Q-band, which is consistent with an enhanced energy splitting between the $\mathrm{a}_{1 \mathrm{u}}$ and $\mathrm{a}_{2 \mathrm{u}}$ orbitals, or the $\mathrm{E}_{\mathrm{g}}$ orbitals. ${ }^{13,14}$ The absorption spectra suggest that incorporation of triarylamine units via the carbon-carbon triple bonds produces profound perturbation to the ground-state properties of the porphyrin. The fluorescence spectra of porphyrins $\mathbf{1}$ and $\mathbf{5}$ are shown in the inset of Figure 1. The enlargement of the $\pi$-conjugation exhibits the emission characteristics. This is manifested in a red shift of the emission maximum as the $\pi$-delocalization increases. This finding is consistent with the similar trend observed in the absorption spectra.

The effective $\pi$-conjugation of the triarylamine moieties via acetylene bridges is expected to reflect on the electrochemical behavior of porphyrins 3-7. The electrochemical data of the porphyrin-triarylamine conjugates are listed in Table 1. It is well-known that both the porphyrin and triarylamine units are redox active. In general, the former has two oxidation and two reduction processes and the latter

(12) Taylor, P. N.; Wylie, A. P.; Huuskonen, J.; Anderson, J. L. Angew. Chem., Int. Ed. 1998, 37, 986-989.

(13) LeCours, S. M.; DiMagno, S. G.; Therien, M. J. J. Am. Chem. Soc. 1996, 118, 11854-11864.

(14) Odobel, F.; Suresh, S.; Blart, E.; Nicolas, Y.; Quintard, J.-P.; Janvier, P.; Questel, J.-Y. L.; Illien, B.; Rondeau, D.; Richomme, P.; Häupl, T.; Wallin, S.; Hammarström, L. Chem. Eur. J. 2002, 8, 3027-3046.

(15) Schauer, C. K.; Anderson, O. P.; Eaton, S. S.; Eaton, G. R. Inorg. Chem. 1985, 24, 4082-4086.

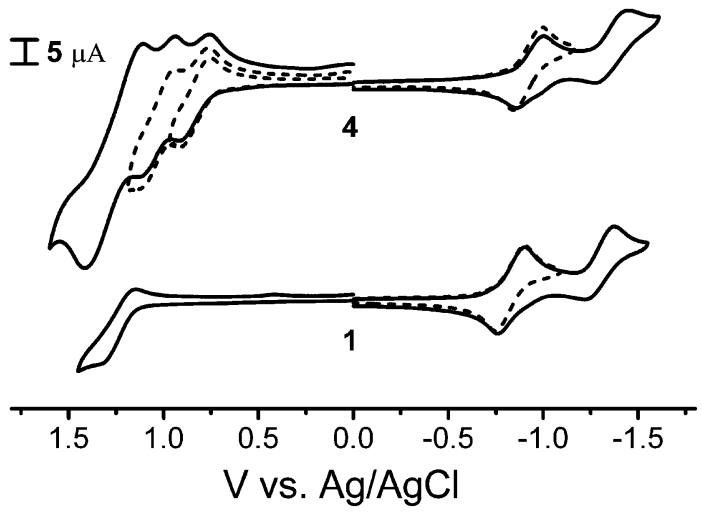

Figure 2. The cyclic voltammograms of $\mathbf{1}$ and $\mathbf{4}$ in THF containing $0.1 \mathrm{M} \mathrm{TBAPF}_{6}$. Dashed lines show narrower scanned ranges.

exhibits one reversible oxidation. Figure 2 shows the cyclic voltammograms of porphyrins $\mathbf{1}$ and $\mathbf{4}$. For porphyrin $\mathbf{4}$, the first two one-electron oxidations at $E_{1 / 2}=+0.84$ and +0.99 $\mathrm{V}$ can be assigned to porphyrin-centered processes, which were further comfirmed by spectroelectrochemistry as will be discussed later on. The two-electron process at $E_{1 / 2}=$ $+1.26 \mathrm{~V}$ corresponds to the oxidation for two of the triarylamine units. As compared to that of porphyrin 1, the first oxidation of porphyrin 4 is anodically shifted by 400 $\mathrm{mV}$, indicating that the triarylamine units can stabilize the oxidized porphyrin core. Interestingly, except for porphyrin 7 the reduction processes of $\mathbf{3}-\mathbf{6}$ exhibit slight shift in the range 0 to $70 \mathrm{mV}$ relative to those of porphyrin 1 , suggesting that the LUMO energy is only slightly perturbed as the $\pi$-conjugation is expanded. In agreement with the absorption and emission measurements, the potential difference between the HOMO and LUMO gap (estimated by $\Delta E=E_{1 / 2}(\mathrm{ox} 1)$ $-E_{1 / 2}($ red1)) decreases with increasing $\pi$-conjugation. For example, the voltammetric HOMO-LUMO gap of $+1.76 \mathrm{~V}$ for porphyrin 4 is smaller by $380 \mathrm{mV}$ than that of porphyrin 1. The contraction of the HOMO-LUMO energy gap in $\mathbf{4}$ is attributed to the elevated HOMO energy.

Substituent effects of porphyrins 3-7 on the redox potentials were observed. For example, the first oxidation for porphyrin 5 occurred at $E_{1 / 2}=+0.76$ while that for porphyrin 7 was observed at $E_{1 / 2}=+1.06$. Considering the long distance of about $12 \AA$ between the substituents of the triarylamine units and the porphyrin core, such a large difference in the redox potential is remarkable.

The electrochemical reactions of our compounds were also studied by spectroelectrochemistry. The spectral changes of compound $\mathbf{4}$ at applied potentials of $E_{\text {appl. }}=+0.90$ and +1.15 $\mathrm{V}$ show a sharp decrease in the Soret band, indicating that the oxidations occur at the porphyrin ring. The most striking feature of the spectra for both one- and two-electron oxidized species is the presence of the broad near-IR band, which can be ascribed to the charge transfer between the triarylamine units and the porphyrin cation/dication. ${ }^{7 \mathrm{c}, 8}$ The first two one-electron oxidation processes are reversible. How- 


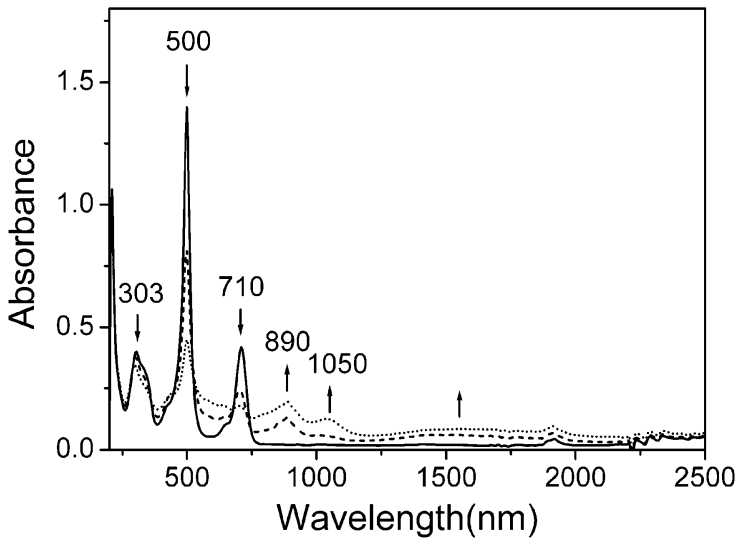

Figure 3. Spectral changes of 4 in THF containing $0.1 \mathrm{M} \mathrm{TBAPF}_{6}$ at applied potentials of +0.70 (solid), +0.90 (dash), and $+1.15 \mathrm{~V}$ (dot).

ever, further oxidation at an applied potential of $+1.35 \mathrm{~V}$ leads to decomposition of the complex.

Figure 4 shows the ORTEP diagram of compound 3 . The zinc ion is coordinated to a THF molecule. The bond distances and angles in the porphyrin ring are similar to those observed in the 5,10,15,20-tetraarylporphyrin system. ${ }^{15,16}$ The porphyrin framework is essentially planar. The acetylene carbons slightly deviate from the mean plane of the porphyrin in the range 0.008 to $0.136 \AA$. Strong electronic interaction requires efficient $\pi$-orbital overlap and this can be examined by the dihedral angles between the aromatic rings. The dihedral angles between the acetylene-bonded benzene rings and the porphyrin macrocycle are $15.41^{\circ}, 15.41^{\circ}, 18.69^{\circ}$, and $24.78^{\circ}$, respectively, which are smaller than those of $29.7^{\circ}$ and $59.5^{\circ}$ observed in meso-tetra(4-butylphenylethynyl)porphyrin zinc. ${ }^{4 a}$ The distances of carbon-carbon triple bonds fall into the range 1.193-1.201 $\AA$, indicating that there is no cumulenic character in this compound. It is noteworthy that the porphyrin shows strong $\pi-\pi$ interaction with a plane-plane distance of $3.30 \AA$, which is shorter by $0.26 \AA$ than that observed in meso-tetra(4-butylphenylethynyl)porphyrin zinc. ${ }^{4 a}$

In conclusion, we have successfully synthesized a series of star-shaped porphyrin-triarylamine conjugates. Their optical and electrochemical properties show that the introduction of triarylamine units via acetylene bridges signifi-

(16) Scheidt, W. R.; Kastner, M. E.; Hatano, K. Inorg. Chem. 1978, 17, 706-710.
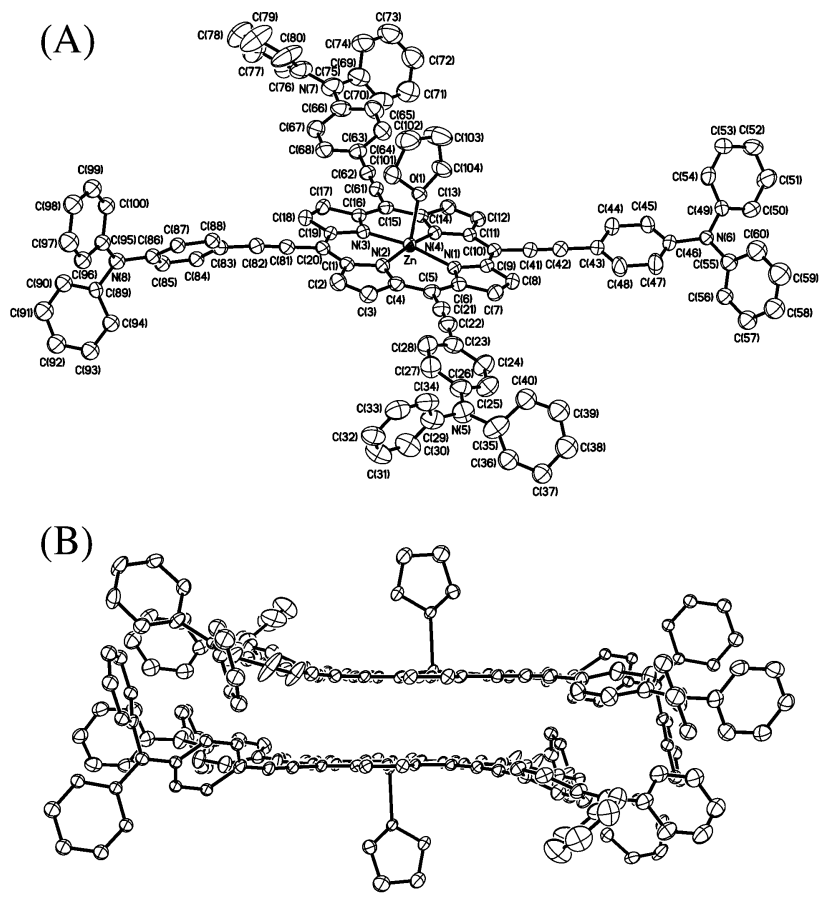

Figure 4. (A) Crystal structure of 3. (B) Stacking pair of 3 with a plane-plane distance of $3.30 \AA$ A. Thermal ellipsoids were drawn at $50 \%$ probability levels.

cantly extends the $\pi$-conjugation of the porphyrin core. These new compounds exhibit large red shifts of Soret and Q-bands and these studies may lead to the development of new photosensitizers for applications in photodynamic therapy. The strong $\pi-\pi$ interaction of $\mathbf{3}$ in the solid state suggests that upon proper modification this type of porphyrin may form columnar stacking supramolecules, which can be considered as "molecular wires" and may be used for chargetransporting or light-harvesting. Study along this line is currently underway in our laboratory.

Acknowledgment. We thank the National Science Council of Taiwan for financial support. We also thank Professor Kuan-Jiuh Lin (National Chung Hsing University) for the access of the UV-vis-near-IR spectrometer.

Supporting Information Available: Synthetic procedures, spectral data, and cyclic voltammograms for new compounds, and crystallographic data for $\mathbf{3}$. This material is available free of charge via the Internet at http://pubs.acs.org.

OL061478W 